salient features of undergraduate medical education in 87 countries of the world, tho material having beon provided by the health authorities of the countries concerned or by the medical schools themselves. To this has been added information about the admission of foreign students to medical schools and about the conditions which govern medical practice by nationals with foreign qualifications or by foreigners who have qualified in the country concerned. There is also information about the laws which govern medical practice in some countries which have no medical schools. Tables show the number of years of medical education required in each country and other conditions that must be fulfilled before a licence to practice is granted. It is interesting to note that, while most countries require a practitioner to complete at least one year of experience in a hospital before he may practise, some countries, such as China and the Sudan, require him to complete two years of such experience; Austria alone requires him to complete three. In some countries one of the years of postgraduate experience is devoted to rural or State service or to specialization and teaching. The Directory also supplies data about the population of the countries concerned, the number of medical schools and physicians, and the number of students who enrol and are admitted and who graduate. An interesting appendix compares the numbers of medical, dental and veterinary schools. It may surprise some readers to learn that whereas the United Kingdom has 6 veterinary schools, Japan has 14, the U.S.S.R. 23, the United States 18 and India 16. A study of these pages will enable the reader to obtain what is, in effect, an overall picture of medical education all over the world. It is clear that the total number of years spent, including primary and secondary education, before practice is allowed varios little all over the world. In most countries primary and secondary education followed by pre-medical, medical and hospital experience add up to some $19-20$ years of training, while in the Lebanon and the United States the total is 21 years. The time devoted specifically to medical education varies little, being usually 4-6 years.

\section{The Registrar General's Quarterly Return for England and Wales}

THE Registrar General's return for the first quarter of 1964 shows that 220,000 live births were registered in that quarter as against 222,000 in the corresponding quarter of last year (The Registrar General's Quarterly Return for England and Wales: Births, Deaths and Marriages; Infectious Diseases; Weather; Population Estimates, Quarter ended 31st March, 1964. Pp. 28 (No. 46, lst Quarter, 1964.) (London : H.M.S.O., 1964.) 2s.6d.net). However, Easter fell in the last week of March, and this may have delayed some of the registrations. The preliminary seasonally adjusted figure shows 213,000 births, as against 212,000 for the corresponding quarter of 1963 ; this is slightly lower than the figure for the last quarter of $1963(213,300)$ and below the peak figure for the third quarter of $1963(215,400)$. The death rate in the quarter was low at $13 \cdot 4$, reflecting the relatively mild winter. Infant mortality at 22 per 1,000 live births is once again a record low figure for the first quarter. It will be interesting to see whether the figures for the second quarter of 1964 will show a continuation of the decline in the number of births and of the birth rate. The report contains, as is usual in March, a brief analysis of causes of death in 1963. There were only 7 deaths from acute poliomyelitis, the lowest number ever recorded, compared with 18 in 1962, and an annual average of 262 in 1951-53. Deaths from lung cancer increased by 3 per cent for men and 5 per cent for women, compared with 1962, whereas deaths from all malignant neoplasms increased by only 0.8 per cent. Motor vehicle accidents accounted for 6,400 deaths compared with 6,300 in 1962 and 6,600 in 1961 .

\section{Radio-isotopes in Hydrology}

THE report of the panel on the use of isotopes in hydrology which met in Vienna during December 17-21, 1962, has now been issued (Technical Report Series, No. 23: Isotope T'echniques for Hydrology. Pp. 36. Vienna: International Atomic Energy Agency; London: H.M.S.O., 1964. 21 schillings; $6 s . ; 1$ dollar). More detailed discussions on some of the techniques mentioned by the panel were presented at an International Atomic Energy Agency symposium in Tokyo during March 5-9, 1963, and are published in Radioisotopes in Hydrology (I.A.E.A., Vienna, 1963). Ground-water dating techniques, including carbon-14, silicon-32 and tritium dating, are discussed in detail in the report, together with short-term groundwater tracing by techniques involving stable isotopes and activation analysis. It is recommended that the exchange of carbon between the liquid and solid phases in groundwater be investigated by tracing experiments in which tritium in tritiated water and carbon-14 as bicarbonate are used simultaneously. There are many unresolved questions regarding ground-water recharge rates, which depend on climate, season, geography, geochemistry, topography and vegetation, and until more is known the interpretation of ground-water age from tritium concentration data must be treated with caution. One section of the report deals with field experiments, covering investigations in the Snake River Plain, Idaho; an underground connexion in New Mexico; the determination of an aquifer by multiple-well tracing; and reservoir leakage, and another section with specific ground-water problems in Greece, on Kilimanjaro, and in the desert.

The panel concluded that isotope-technique applications to hydrological problems have been somewhat useful in the understanding of the nature of the hydrologic cycle and in the solution of specific engineering problems. However, additional rescarch and development are required on the part of both hydrologists and isotope specialists, preferably working together as teams, to ensure the proper synthesis of scientific advances in their respective ficlds and the translation of these advances into practical technology. In particular, it considered that the present International Commission on Radiological Protection values, which are used as standards for exposure for large populations and which are based on long-term exposure, are too restrictive for short-term experiments such as are required in hydrological investigations.

\section{Isotope Dilution Analysis}

THE monograph Radioactive Isotope Dilution Analysis is one of the series of occasional publications of the Radiochemical Centre, Amersham (Pp. 12. Amersham: The Radiochemical Centre, 1964). Classical methods of chemical analysis generally rely either on the quantitative isolation of the component to be determined or on the measurement of some specific chemical or physical property of the component which is not obscured by other substances present. These methods often fail with more complex mixtures, and then isotope dilution analysis may be suitable. The basic principle is that if a radioactive tracer is mixed with the corresponding unlabelled compound the amount of activity per gram of the substance will be reduced, and that if the reduction per gram is measured the amount of diluting material can be caleulated. The calculation and method of procedure are explained in the monograph and illustrated by an example. New developments in the field of dilution analysis, particularly derivative dilution where it is necessary to determine one component in the presence of several others, and saturation analysis which involves the use of a binding agent specifio for the compound being determined, are explained in some detail. The examples discussed are mainly of organic substances but, as is shown in the final section of the monograph, direct isotope dilution can be applied equally well to inorganic substances. The mono- 